\title{
TrkB Has a Cell-Autonomous Role in the Establishment of Hippocampal Schaffer Collateral Synapses
}

\author{
Bryan W. Luikart, ${ }^{1}$ Serge Nef, ${ }^{1}$ Tuhin Virmani, ${ }^{2}$ Mark E. Lush, ${ }^{1}$ Yajuan Liu, ${ }^{1}$ Ege T. Kavalali, ${ }^{2}$ and Luis F. Parada ${ }^{1}$ \\ ${ }^{1}$ Center for Developmental Biology and Kent Waldrep Foundation Center for Basic Neuroscience Research on Nerve Growth and Regeneration and ${ }^{2}$ Center \\ for Basic Neuroscience, University of Texas Southwestern Medical Center, Dallas, Texas 75390-9133
}

\begin{abstract}
Neurotrophin signaling has been implicated in the processes of synapse formation and plasticity. To gain additional insight into the mechanism of BDNF and TrkB influence on synapse formation and synaptic plasticity, we generated a conditional knock-out for TrkB using the cre/loxp system. Using three different cre-expressing transgenic mice, three unique spatial and temporal configurations of TrkB deletion were obtained with regard to the hippocampal Schaffer collateral synapse. We compare synapse formation in mutants in which TrkB is ablated either in presynaptic or in both presynaptic and postsynaptic cells at early developmental or postdevelopmental time points. Our results indicate a requirement for TrkB at both the presynaptic and postsynaptic sites during development. In the absence of TrkB, synapse numbers were significantly reduced. In vivo ablation of TrkB after synapse formation did not affect synapse numbers. In primary hippocampal cultures, deletion of TrkB in only the postsynaptic cell, before synapse formation, also resulted in deficits of synapse formation. We conclude that TrkB signaling has a cell-autonomous role required for normal development of both presynaptic and postsynaptic components of the Schaffer collateral synapse.
\end{abstract}

Key words: BDNF; varicosity; hGFAP-cre; CaMKII-cre; synapsinI-cre; spine

\section{Introduction}

The neurotrophin gene family, which consists of nerve growth factor, brain-derived neurotrophic factor (BDNF), neurotrophin-3, and neurotrophin $4 / 5$, is classically known for its influence on survival, differentiation, and growth of neurons in the peripheral nervous system. However, these genes and their Trk family receptors are also abundant in the developing CNS. Knock-out approaches have revealed altered survival, differentiation, and arborization of CNS neurons (Minichiello and Klein, 1996; Xu et al., 2000; Gorski et al., 2003a), although less severe than seen in the PNS (Klein et al., 1993; Jones et al., 1994; Luikart et al., 2003). Loss of function studies of BDNF and TrkB have also revealed influences on the emergent affective and cognitive states of mice (Minichiello et al., 1999; Kernie et al., 2000; Gorski et al., 2003b). Although these behavioral effects may, in part, be attributable to influence on cell survival and differentiation, they may also arise from the requirement for TrkB signaling in acute modulation of synaptic transmission, synapse formation, and the activity-dependent remodeling of synaptic connectivity (Poo, 2001; Cohen-Cory, 2002).

There is evidence that TrkB signaling is important for the formation of both inhibitory and excitatory synapses. Exogenous

\footnotetext{
Received Jan. 5, 2005; revised Feb. 16, 2005; accepted March 1, 2005.

We thank Drs. David R. Kaplan, Louis F. Reichardt, and Masahiko Watanabe for the generous supply of TrkB and PSD-95 antibodies, Dr. Xinran Liu for guidance with the electron microscopy in this manuscript, and George Lawton, Allison Jordon, and Christina Nelson for technical assistance. We also thank Drs. Thomas C. Sudhof, Steve G. Kernie, and Tonya Luikart for critical readings of this manuscript.

Correspondence should be addressed to Dr. Luis F. Parada, Center for Developmental Biology and Kent Waldrep Foundation Center for Basic Neuroscience Research on Nerve Growth and Regeneration, University of Texas Southwestern Medical Center, 6000 Harry Hines Boulevard, Dallas, TX75390-9133. E-mail: luis.parada@utsouthwestern.edu.

DOI:10.1523/JNEUROSCI.0041-05.2005

Copyright $\odot 2005$ Society for Neuroscience $\quad 0270-6474 / 05 / 253774-13 \$ 15.00 / 0$
}

application of BDNF to embryonic day 16.5 (E16.5) cultured neurons elicits the precocious formation of electrophysiologically active excitatory and inhibitory synapses (Vicario-Abejon et al., 1998; Collin et al., 2001). In agreement with these in vitro studies, it has been shown that overexpression of BDNF in transgenic animals using the nestin promoter elicits an increased number of both excitatory and inhibitory synapses by E18.5 (Aguado et al., 2003). In the developing retinal-tectal system of Xenopus, axonal elaboration and synapse formation have been observed in vivo, and the injection of BDNF enhances synapse formation and the accompanying axonal elaboration (Alsina et al., 2001). In loss-of-function studies, TrkB is required for the establishment of cerebellar inhibitory synapses in healthy TrkB conditional knock-out animals (Rico et al., 2002). Electron microscopic studies of the subset of TrkB knock-out animals that survive until postnatal day 13 (P13) show decreased numbers of hippocampal Schaffer collateral excitatory synapses (Martinez et al., 1998). The specificity of TrkB involvement in this synaptic reduction has been questioned because the TrkB knock-out animals are unhealthy and few survive past 1 week of age. Additionally, with more global knock-outs, it has been impossible to determine whether these synaptic requirements for TrkB are at the cell-autonomous level or indirect.

In the present study, we use a conditional knock-out approach to selectively ablate TrkB expression in three different temporal and spatial configurations with regard to the mouse hippocampal Schaffer collateral synapse. Our results provide direct genetic evidence that TrkB is necessary for the formation of a substantial subset of excitatory synapses in healthy animals. We demonstrate that this effect is expressed in the temporal window of activitydependent synapse formation and is associated with structural 
modifications of axons and dendrites at the level of varicosities (VARs) and spines. Furthermore, the specific genetic ablation of TrkB in presynaptic, postsynaptic, or both presynaptic and postsynaptic neurons in vivo or in vitro demonstrates that TrkB mediates synapse formation via cell-autonomous mechanisms.

\section{Materials and Methods}

Generation of conditional knock-out mice. Using homologous recombination in embryonic stem (ES) cells, we generated mice with a $3 \mathrm{~kb}$ region containing both transcription initiation sites and the first coding exon of the TrkB gene flanked with floxp sites (Luikart et al., 2003).

$\beta$-Galactosidase staining and immunohistochemistry. P60 animals were transcardially perfused with PBS, followed by $4 \%$ paraformaldehyde (PFA) (solutions were kept on ice during perfusion). The brains were dissected and postfixed in $4 \%$ paraformaldehyde for $2 \mathrm{~h}$ at $4^{\circ} \mathrm{C}$. Coronal sections, $50 \mu \mathrm{m}$ thick, were made using a vibratome (Leica, Nussloch, Germany). Free-floating sections were stained for $16 \mathrm{~h}$ with a solution consisting of PBS with $0.1 \mathrm{M}$ potassium ferricyanide, $0.1 \mathrm{M}$ potassium ferrocyanide, $1 \mathrm{M} \mathrm{MgCl}_{2}$, and $1 \mathrm{mg} / \mathrm{ml}$ 5-bromo-4-chloro-3-indolyl- $\beta$ D-galactopyranoside in dimethylformamide (all from Sigma, St. Louis, $\mathrm{MO})$. Sections were then rinsed with PBS and counterstained with nuclear fast red. Double-labeling immunohistochemistry was also performed on free-floating sections using a polyclonal (rabbit) antibody to $\beta$-galactosidase (1:1000; catalog \#986; Chemicon, Temecula, CA) and a monoclonal antibody to the neuronal-specific nuclear protein NeuN (1:1000; Chemicon).

In situ hybridization. In situ hybridization was performed as described previously (Luikart et al., 2003) with some modifications to the tissue processing. Brains of P60 animals were acutely dissected and frozen, and $10 \mu \mathrm{m}$ coronal sections were made using a cryostat (Micron, Walldorf, Germany). All sections shown in this paper were hybridized and developed in parallel, and equal exposure times were used to show relative signal intensities for the different mutant mice. Radioactive $\left({ }^{35} \mathrm{~S}\right)$ antisense cRNA was produced by in vitro transcription with T7 RNA polymerase from linearized clones from TrkB kinase domain (amino acids $570-703,420$ bp fragment).

Tissue processing and staining of synapses. P60 animals were killed by rapid decapitation, and the middle one-third of the hippocampus with its associated cortex was dissected and postfixed in 4\% PFA overnight. The tissue was then processed and embedded in paraffin, and serial $5 \mu \mathrm{m}$ sections were made in the transverse plane. Synaptic staining was performed as described previously (Fukaya and Watanabe, 2000). Sections were deparafinized with xyline, hydrated, and treated with pepsin (Sigma). Before pepsin digestion, sections were warmed to $37^{\circ} \mathrm{C}$ in distilled water. Digestion buffer $(0.2 \mathrm{~N} \mathrm{HCl}$ in water $)$ was also prewarmed, and frozen aliquots containing $10 \mathrm{mg} / \mathrm{ml}$ pepsin solution were thawed just before use and added to the $0.2 \mathrm{~N} \mathrm{HCl}$ to a final concentration of $0.566 \mathrm{mg} / \mathrm{ml}$. Sections were washed with distilled water, permeabilized with PBS with $0.3 \%$ Triton X-100 for $30 \mathrm{~min}$, and blocked with 6\% NGS in PBS for $30 \mathrm{~min}$, and antisera were applied overnight at $4^{\circ} \mathrm{C}$. Monoclonal synaptophysin (Sigma) and polyclonal postsynaptic density-95 (PSD-95) (provided by Masahiko Watanabe, Hokkaido University School of Medicine, Sapporo, Japan) were used at a 1:200 dilution. Secondary antibodies (cyanine 5 anti-mouse and cyanine 3 anti-rabbit; Jackson ImmunoResearch, West Grove, PA) were applied at 1:400 for $1 \mathrm{~h}$.

Comparison of neuron number and CA region volume. Slides adjacent to those used for the synapse quantitation portion of this study were stained using $4^{\prime}, 6^{\prime}$-diamidino-2-phenylindole (DAPI) stain (1:2000). All images were obtained and quantitated blind to the animal genotype. For each animal, 4-12 sections were stained. Images of equivalent regions of areas CA1 and CA3 were obtained using an Olympus Optical (Tokyo, Japan) microscope with a $20 \times$ objective. Using MetaMorph software (Universal Imaging Corporation, West Chester, PA), a square region with an area of $40,000 \mu \mathrm{m}^{2}$ was placed on the image, and the number of DAPI-stained nuclei in the pyramidal cell layer was manually counted. An average number from all stained slides was determined for each animal. To examine the total volume of the pyramidal cell layer, serial $50-\mu \mathrm{m}$-thick vibratome sections were made and stained with DAPI, and the area of the pyramidal cell layer was measured in individual images. This was then multiplied by the thickness of the section and the total number of sections to obtain volume. Statistical comparison between control and knock-out animals was made using a two-tailed, two-sample equal variance $t$ test ( $n$ is number of animals per group).

Synapse quantitation. The synapse quantitation was performed essentially as first described (Bozdagi et al., 2000). To increase the consistency of staining, all sections used for the synapse quantitation of this study were stained in parallel as one group. All images were taken and quantitative data were collected by an investigator blind to the animal genotype. Care was taken to ensure that sections stained were from precisely anatomically equivalent regions.

Images, $1024 \times 1024$, were made on a LSM 510 laser-scanning confocal microscope (Zeiss, Oberkochen, Germany) using a 100× 1.4 numerical aperture oil-immersion objective at a $3 \times$ zoom. A single optical section $(0.8 \mu \mathrm{m}$ thick) from stratum radiatum of CA1 was taken from each tissue section, and five sections were analyzed per animal. All microscope settings were unchanged from section to section, except for the detector gain. The detector gain was adjusted so that all images covered an equivalent range of intensity values in the histogram function of the LSM510 software. Before analysis, levels were further adjusted relative to the histogram, thus equalizing the range of pixel intensity values in all images. An investigator blind to genotype obtained quantitative data using MetaMorph software in which a thresholding function was used to exclude from analysis all but immunolabeled puncta. The same threshold value was applied to all quantitated images. The number of discrete puncta that had been thresholded was measured. A size exclusion filter was applied so as to exclude background objects that were under 20 pixels ${ }^{2}\left(0.02 \mu \mathrm{m}^{2}\right)$ in area. The average synaptic puncta area was determined to be 250 pixels $^{2}\left(0.2 \mu \mathrm{m} / \mathrm{m}^{2}\right)$ for PSD-95 and 320 pixels $^{2}(0.29$ $\mu \mathrm{m}^{2}$ ) for synaptophysin. The count was adjusted by dividing all puncta that were over two times the average puncta size by that standard value. This adjustment was applied to separate puncta so near one another that they were thresholded as one object. Hand counts of a subset of images performed by three separate blind counters confirmed the data obtained with the computer counting method. Data from each section were averaged to produce a single average synaptic density value for each animal. No significant difference in synapse number arose between littermate floxed and cre control animals of the three different mutant types. All controls were thus grouped, and the groups of animals were compared using a two-tailed, two-sample equal variance $t$ test.

Quantification of spine density and dendritic arborization. Animals were perfused with cold PBS, and the whole brain placed in Golgi solution for $12 \mathrm{~d}$. Vibratome sections, $100 \mu \mathrm{m}$ thick, were made, and images of dendrites within the area CA1 stratum radiatum were made using a $62 \times$ objective with an Olympus Optical microscope and a cooled CCD camera. Using MetaMorph software, a dendritic region that was clearly in focus was traced to measure its length. The number of spines on that region was then manually quantitated and divided by the region length to obtain spine density. No correction was made for spines out of focus in the z-plane.

To estimate total dendritic arborization, TrkB knock-out animals were crossed to Thyl green fluorescent protein (GFP) line M mice (Feng et al., 2000). Vibratome sections, $100 \mu \mathrm{m}$ thick, were made, and $\mathrm{z}$-series were obtained using an LSM510 confocal microscope (Zeiss). Using the $20 \times$ objective, the apical dendritic arbor was imaged. Only neurons whose cell bodies were in the middle one-third of the z-plane were used in the study. Dendritic arbors were reconstructed by manually tracing image stacks in MetaMorph software. Total dendritic arborization was measured as the sum of lengths of the traced regions. No adjustment was made to this value for dendritic length through the z-planes.

Electron microscopy. General electron microscopy procedures were performed as described previously (Biederer et al., 2002). Animals were perfused with a solution of $3 \%$ paraformaldehyde and $1 \%$ glutaraldehyde in PBS. The brains were then dissected out and postfixed overnight in 3\% paraformaldehyde and $2 \%$ glutaraldehyde. Square blocks, $500 \mu \mathrm{m}$, of the middle one-third of the hippocampus were then cut using a Leica vibratome. These were then fixed with $1 \%$ osmium tetroxide and embedded. Sections, $60 \mathrm{~nm}$ thick, were cut on the Leica Ultracut UCT mic- 
rotome. Sections were collected on 200 mesh copper grids and stained with uranyl acetate and lead citrate. Sections were imaged on the Jeol (Peabody, MA) 1200 EX TEM at a magnification of $40,000-50,000 \times$. Images were collected at a distance of $100-200 \mu \mathrm{m}$ from the CA1 pyramidal cell bodies. For quantitative analysis, a total of 40-50 images were collected per section (each with an area of $8250 \mu \mathrm{m}^{2}$ ), and two sections were imaged from each of four control, two TrkB $\times$ synapsinI-cre, and two TrkB $\times$ hGFAP-cre animals. Thus, a total of 424 images were quantitated in anatomically equivalent regions of the CA1 stratum radiatum. Those elements quantified are essentially as defined previously (Sorra and Harris, 1993; Jourdain et al., 2002). A blind counter quantitated the number of postsynaptic densities (only thickened densities of asymmetric synapses were counted), varicosities (defined by the presence of three or more synaptic vesicles), perforated synapses (defined as discontinuous postsynaptic densities), and multi-synapse boutons (MSBs) (defined as two or more postsynaptic densities from different spines interacting with a single varicosity). For statistical analysis, the average number of these elements per section was compared. Thus, $n=8$ sections from 4 animals, 4 sections from 2 animals, and 4 sections from 2 animals for control, TrkB $\times$ GFAP-cre, and TrkB $\times$ synapsinI-cre animals, respectively.

Axon tracing. Hippocampal slices, $400 \mu \mathrm{m}$ thick, were made on a Leica vibratome in icecold Hibernate A supplemented with B27

(BrainBits, Springfield, IL). Slices were then placed in dishes containing matrigel diluted 1:3 with Neurobasal A supplemented with B27 (Invitrogen, Gaithersburg, MD). Using a Nanoliter 2000 injector (World Precision Instruments, Sarasota, FL), $4 \mathrm{nl}$ of 10\% Alexa 488-conjugated dextran was injected into the $\mathrm{CA} 3$ region. The slices were allowed to trace for $6 \mathrm{~h}$ at $37^{\circ} \mathrm{C}$ in Neurobasal A. The slices were then fixed and resectioned to $50 \mu \mathrm{m}$ with a Leica vibratome and imaged on the LSM510 confocal microscope. Intervaricosity distance was measured by tracing axon segments using MetaMorph software.

Cell culture. Dissociated hippocampal cultures were prepared from 1-d-old TrkB flx/flx or wild-type mice as described previously (Kavalali et al., 1999) and transfected after 5 days in vitro (DIV) using a calcium phosphate transfection protocol. Constructs used for transfections were made by cloning the cre sequence into the pAdTrack-cytomegalovirus vector.

Electrophysiology. Whole-cell recordings from pyramidal cells after $10-11 \mathrm{~d}$ in vitro were acquired with an Axopatch 200B amplifier and Clampex 8.0 software (Axon Instruments, Union City, CA). Recordings were filtered at $2 \mathrm{kHz}$ and sampled at $200 \mu$ s. Pipette internal solution included the following (in $\mathrm{mm}$ ): $115 \mathrm{Cs}-\mathrm{MeSO}_{3}, 10 \mathrm{CsCl}, 5 \mathrm{NaCl}, 10$ HEPES, 0.6 EGTA, 20 tetraethylammonium-Cl, $4 \mathrm{Mg}^{2+}$-ATP, 0.3 $\mathrm{Na}_{2} \mathrm{GTP}$, and 10 QX-314 (lidocaine $N$-ethyl bromide), pH 7.35 (300 mOsm). Modified Tyrode's solution [containing $150 \mathrm{~mm} \mathrm{NaCl}, 4 \mathrm{~mm}$ $\mathrm{KCl}, 2 \mathrm{~mm} \mathrm{MgCl}_{2}$, $10 \mathrm{~mm}$ glucose, $10 \mathrm{~mm}$ HEPES, $2 \mathrm{~mm} \mathrm{CaCl}_{2}, 1 \mathrm{~mm}$ TTX, pH $7.4(\sim 310 \mathrm{mOsm})$, and $1 \mu \mathrm{M}$ picrotoxin] was used as extracellular bath solution in all experiments. For the glutamate flow through, the above solution also contained $1 \mathrm{~mm}$ glutamate.

Quantitative Western blots. Hippocampus or cortex was dissected, and synaptic proteins were isolated by subcellular fractionation. All protein used for quantitative analysis was purified in parallel on the same day. After dissection, all steps were performed at $4^{\circ} \mathrm{C}$. Tissue was homogenized in 10\% (w/v) of homogenization buffer (HB) [320 mm sucrose, 4 mM HEPES, pH 7.4, and 1 Roche Products (Welwyn Garden City, UK) complete tablet of protease inhibitors in $50 \mathrm{ml}$ of buffer]. The homoge-
Strategy for Generation of TrkB Flox Allele

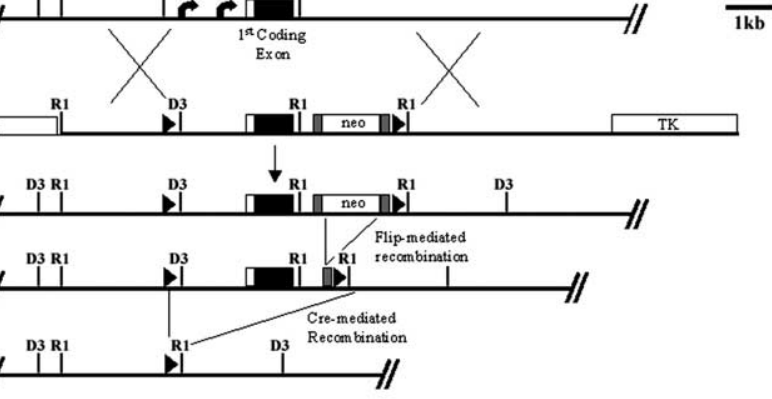

$\mathrm{c}$

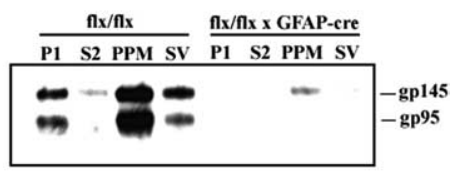

Figure 1. Generation of TrkB conditional knock-out mice. Conditional TrkB knock-out mice were generated by flanking the first ( isolated fractions enriched in large intracellular membranous organelles (P1), cytoplasmic proteins (S2), presynaptic and postsyn-

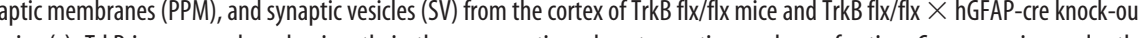
mice (c). TrkB is expressed predominantly in the presynaptic and postsynaptic membrane fraction. Cre expression under the control of the hGFAP promoter in TrkB flx/flx animals results in a dramatic reduction of TrkB full length (gp145) and ablation of truncated TrkB (gp95) in the cortex. This result is consistent with the expression pattern of hGFAP-cre in the cortex.

nate was centrifuged at $1000 \times g$ for $10 \mathrm{~min}$. The pellet $(\mathrm{P} 1)$ was collected, and the supernatant was centrifuged at $12,000 \times g$ for $15 \mathrm{~min}$. The second supernatant was collected as fraction S2. The second pellet was resuspended in $1 \mathrm{HB} / 10 \mathrm{H}_{2} \mathrm{O}$ and homogenized by six strokes in a glass Teflon homogenizer at $2100 \mathrm{rpm}$. The homogenate was spun at 33,000 $\times \mathrm{g}$ for $20 \mathrm{~min}$. The pellet containing presynaptic and postsynaptic membranes was collected. All pellets were resuspended in $20 \mathrm{~mm}$ Tris, $\mathrm{pH} 8.0$, with protease inhibitors, and concentrations were determined using the BCA kit (Pierce, Rockford, IL). Eight to $20 \mu \mathrm{g}$ of each fraction was separated on SDS-PAGE gels and transferred to nitrocellulose membranes.

For Western blot analysis, the following primary antibodies were incubated overnight in 5\% blocking buffer: Reichardt's rabbit polyclonal TrkB, 1:1000; Affinity Bioreagents monoclonal PSD-95, 1:500 (Chemicon); glutamate receptor GluR1, 1:500; GluR2/3, 1:500; NMDA receptor NR1, 1:500; NR2A, 1:500; NR2B, 1:1000; GluR4, 1:500; GluR5, 1:500; GluR6/7, 1:10,000 [all polyclonal antibodies from Upstate Biotechnology (Lake Placid, NY) except when indicated]. Secondary antibodies (Santa Cruz Biotechnology, Santa Cruz, CA) were used at 1:5000 for $1 \mathrm{~h}$. Blots were developed using ChemiGlow West reagent (Alpha Innotech, San Leandro, CA) and photographed using Eastman Kodak (Rochester, NY) Image Station 2000r. The net band intensity was determined using Eastman Kodak 1D Image Analysis software. The quantitative linear range was determined for each antibody by loading a gradient of $8-18 \mu \mathrm{g}$ of total protein from a control animal in parallel with a gel on which protein from four control and four knock-out animals was loaded. Relative percentages of controls versus knock-outs were determined by fitting the intensity values for the experimental animals to the linear curve generated by the loaded gradient. Blots were stripped using $100 \mathrm{~mm}$ $\beta$-mercaptoethanol, $2 \% \mathrm{SDS}$, and $62.5 \mathrm{~mm}$ Tris- $\mathrm{HCl}, \mathrm{pH} 6.7$, at $50^{\circ} \mathrm{C}$ for $30 \mathrm{~min}$ and either reprobed or stained with Sypro Ruby (Molecular Probes, Eugene, OR) as a loading control. Sypro Ruby stain was incubated with the blot with little agitation for 5 min and was washed with water per the instructions of the manufacturer. Blots were dried, and the stain was imaged with a $600 \mathrm{~nm}$ interference filter. The linear range for 

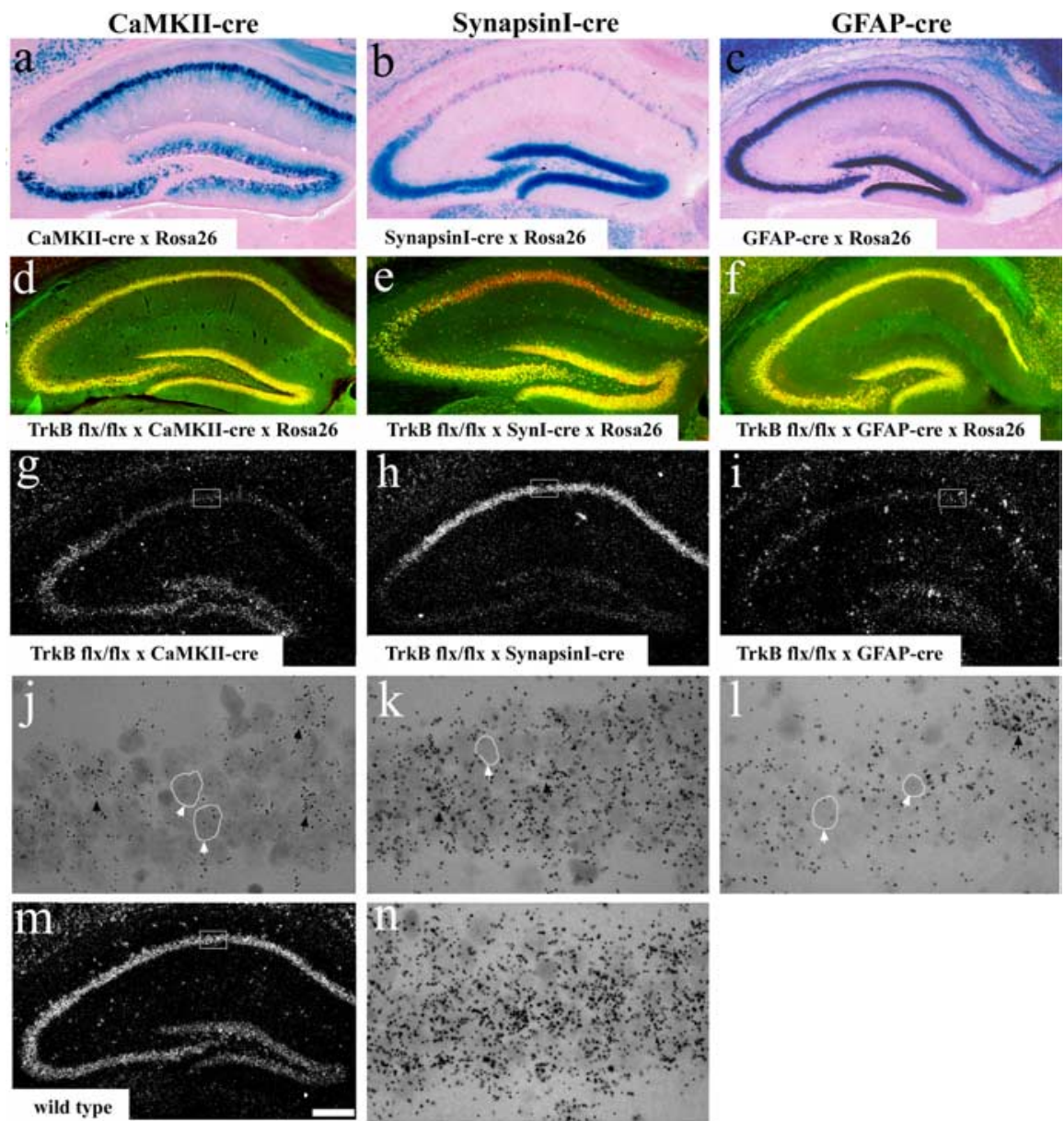

Figure 2. Three patterns of TrkB deletion in the hippocampus. $\beta$-Galactosidase staining of hippocampi from CaMKII-cre (a), synapsinl-cre (b), and hGFAP-cre (c) shows the pattern of recombination within the Rosa-26 lacz reporter allele. Mice homozygous for the TrkB flox allele, heterozygous for the Rosa-26 lacz reporter allele, and bearing the CaMKII-cre (d), synapsinl-cre (e), and hGFAP-cre $(\boldsymbol{f})$ were immunostained for NeuN (red) and $\beta$-galactosidase (green). Coexpression (yellow) of $\beta$-galactosidase and NeuN reveals that cre-mediated recombination is taking place in neurons in the same pattern revealed in mice wild type for the TrkB flox allele $(\boldsymbol{a}-\boldsymbol{c})$. Cre-mediated recombination of the TrkB locus is as predicted from the Rosa26 reporter. In situ hybridization using a probe for the kinase domain of the TrkB transcript in TrkB flx/flx mice expressing the CaMKII-cre ( $\boldsymbol{g})$, synapsinl-cre (h), and hGFAP-cre (i) transgenes shows a reduction in TrkB expression when compared with wild-type mice $(\boldsymbol{m})$. Higher-magnification bright-field images of the CA1 region (squares in $\boldsymbol{g}-\boldsymbol{i}, \boldsymbol{m}$ ) TrkB in situ hybridizations counterstained with hematoxylin demonstrate the loss (circled neurons and white arrows) or maintenance (black arrows) of TrkB on a per-cell basis in TrkB flx/flx $X$ CaMKII-cre $(\boldsymbol{j})$, synapsinl-cre $(\boldsymbol{k})$, and hGFAP-cre $(\boldsymbol{I})$. In high-magnification images of wild-type animals, all cells are positive for $\operatorname{TrkB}(\boldsymbol{n})$. Scale bar, $200 \mu \mathrm{m}$.

the loading control was also determined with the loading gradient. Loading control values were used to normalize the net intensity values for the experimental bands to correct for differences in loading.

\section{Results \\ Conditional deletion of TrkB}

Through the use of cre/loxp and homologous recombination in ES cells, a hypomorphic allele (TrkB flox-neo) (Fig. 1a) and a conditional allele (TrkB flox) (Fig. 1a) of the TrkB gene were generated (Fig. 1a). The gene targeting placed loxp sites flanking the first coding exon and the two initiation of transcription sites. Additionally, the neomycin selection cassette was flanked by DNA sequences recognized by "flip" recombinase (Dymecki, 1996). Western blot analysis of brain tissue from the various combinations of wild-type and floxed alleles revealed that the flox-neo allele produced less protein than wild type, whereas the "flipped"/flox allele that lacked the intronic neo cassette pro- duced apparently wild-type levels of TrkB protein (Fig. 1b). Thus, an allelic series ranging from wild-type levels to complete ablation of TrkB protein can be generated (Fig. 1b).

To further evaluate the ability of cre recombinase to produce recombination at the TrkB locus, we performed Western blots on tissue derived by subcellular fractionation of dorsal cortex from control and knock-out mice. TrkB is predominantly expressed in the presynaptic and postsynaptic membrane fraction of wild-type mice. In contrast, TrkB $\mathrm{flx} / \mathrm{flx}$ mice bred to mice transgenic for Cre recombinase under control of a human GFAP promoter (hGFAP) (Zhuo et al., 2001; Malatesta et al., 2003) causes almost complete ablation of TrkB protein (Fig. 1c). The remaining TrkB expression is likely attributable to residual nonrecombined cortical cells and presynaptic TrkB expressed in axons projecting to the cortex from regions displaying little cre-mediated recombination, such as the thalamus.

\section{Hippocampal TrkB deletion}

TrkB and BDNF have been reported to exert functions on synapse formation, basal synaptic transmission, and long-term potentiation (LTP) at the Schaffer collaterals. We therefore wanted to exploit our conditional TrkB allele to address whether these effects were at least in part attributable to developmental loss versus acute loss of TrkB. In addition, we wanted to address whether TrkB functioned presynaptically, postsynaptically, or at both sites. We performed breedings to generate mice carrying the TrkB flx alleles with transgenic mice expressing cre recombinase. All of the transgenic mice described in this study have been published previously: hGFAPcre, calcium/calmodulin-dependent kinase (CaMKII)-cre (T-50 line), and synapsin1-cre (Tsien et al., 1996; Zhu et al., 2001; Zhuo et al., 2001). We further characterized the hippocampal expression patterns of these animals (see Materials and Methods).

\section{CaMKII-cre (T50 line)}

Transgenic cre expression driven by this promoter begins in a small number of neurons at approximately P18 (Tsien et al., 1996; Zhang et al., 2002), and expression slowly increases over the next 30 d. Recombination occurs throughout Ammon's Horn and in the dentate gyrus. This has been confirmed at P60 using Rosa-26 reporter mouse $\beta$-galactosidase assays, immunocytochemistry, and TrkB in situ hybridization (Fig. $2 a, d, g, j$ ). The efficiency of recombination in neurons is not absolute, and we estimate TrkB loss to be $75-80 \%$ at P60 (supplemental Fig. 1 $a, b$, available at www.jneurosci.org as supplemental material). At P25, the TrkB loss is in only $10 \%$ of the neurons. Thus, ablation of TrkB occurs predominantly after synapse formation in both presynaptic and postsynaptic terminals of Schaffer collaterals. 
Synapsin1-cre

This promoter drives cre recombinase expression in early postmitotic neurons beginning at approximately E12.5 (Zhu et al., 2001). In the hippocampus, this expression is confined to the DG, CA2, and CA3 regions (Fig. 2b,e,h,k) in which $100 \%$ of pyramidal and granule neurons undergo cre-mediated recombination. In the CA1 region, $<10 \%$ of cells undergo recombination. Onset of expression appears to correlate to the time course of differentiation of these neurons. Thus, TrkB expression is completely ablated in presynaptic but not postsynaptic terminals of Schaffer collaterals before synapse formation. This has additionally been demonstrated by Western blot (He et al., 2004).

\section{hGFAP-cre}

This promoter drives cre recombinase expression early in neurogenesis and results in TrkB ablation throughout the hippocampus, including all pyramidal and granule neurons as well as astrocytes in the P60 hippocampus. Thus, in contrast to CaMKIIcre-mediated recombination, these mice afford examination of the consequences of TrkB ablation in presynaptic and postsynaptic terminals during embryonic development (Fig. 2c,f,i,l) (Zhuo et al., 2001; Malatesta et al., 2003).

In contrast to TrkB germ line knockouts that perish throughout the first 2 weeks after birth (Luikart et al., 2003), the resultant conditional knock-out mice were viable in all cases and capable of living into adulthood. However, all transgenic strains exhibited some degree of abnormal behaviors. Both $\operatorname{TrkB} \mathrm{flx} / \mathrm{flx} \times$ synapsinI-cre and TrkB flx/flx $\times$ hGFAPcre animals were hyperactive. The TrkB flx/flx $\times$ synapsinI-cre mice had the most overt neurological deficits. They were slightly reduced in size compared with littermates and displayed impaired balancebeam walking and an abnormal hindlimb clasping reflex when suspended by the tail. These neurological deficits underscore the broad and important functions for TrkB in various regions of the CNS outside the hippocampus. The viability of these three transgenic mouse strains, however, permits detailed analysis of the Schaffer collaterals in adult mice and the distinction of developmental versus postdevelopmental effects.

In the conditional knock-out mouse with the most severe hippocampal ablation (TrkB $\times$ hGFAP-cre), we observed no changes in the differentiated state of neurons or astrocytes using the markers NeuN, microtubule-associated protein
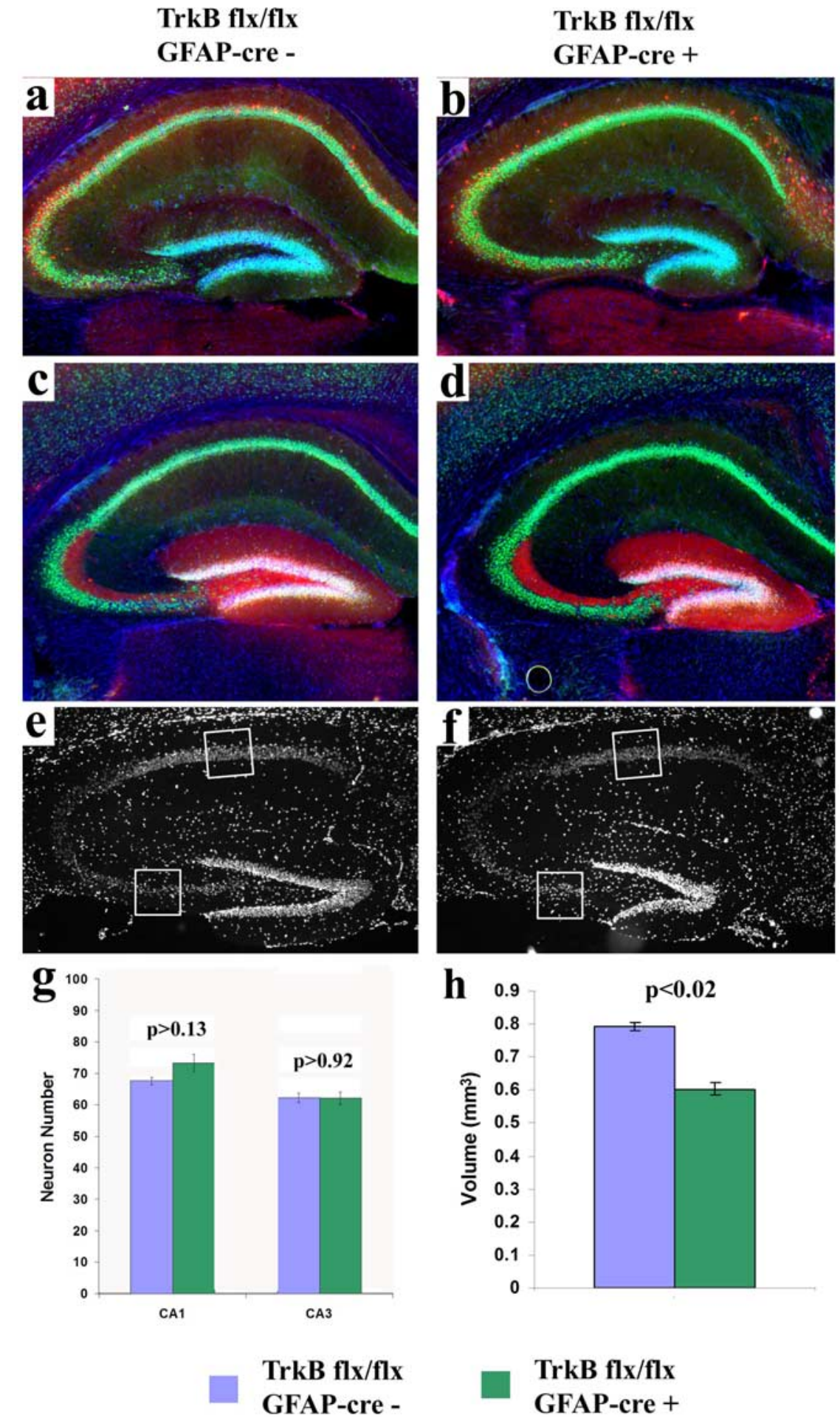

Figure 3. Normal neuronal density in the CA1 and CA3 regions of TrkB $\times$ hGFAP-cre knock-out animals. DAPI (blue), $\beta$-galactosidase (green), and parvalbumin (red) staining of hippocampi from TrkB wild-type $\times$ GFAP-cre $\times$ Rosa- 26 (a) versus TrkB flx/flx $\times$ GFAP-cre $\times$ Rosa-26(b) mice reveals recombination in few hippocampal parvalbumin-positive interneurons, with no deficits observed in those having undergone recombination. DAPI (blue), $\beta$-galactosidase (green), and calbindin (red) staining of hippocampi from TrkB wild-type $\times$ GFAP-cre $\times$ Rosa-26 (c) versus TrkB flx/flx $\times$ GFAP-cre $\times$ Rosa-26 (d) mice reveals recombination in calbindin-positive granule neurons. However, no changes in the gross organization of the mossy fiber pathway were observed. $\boldsymbol{e}, \boldsymbol{f}$, DAPI-stained hippocampi of TrkB flx/flx $(\boldsymbol{e})$ and TrkB flx/flx $\times$ hGFAP-cre $(\boldsymbol{f})$ animals. Comparison of pyramidal neuron density was determined by quantitating the average cell number in a defined region of control versus TrkB $\mathrm{flx} / \mathrm{flx} \times$ hGFAP-cre animals. The number of DAPI-stained nuclei in the pyramidal cell layer of the CA1 and CA3 regions was counted within a $40,000 \mu \mathrm{m}^{2}$ area (squares in $\boldsymbol{e}, \boldsymbol{f}$ ). The average neuron numbers from four control and five knock-out animals reveal no significant difference in neuron density between these groups within a defined region of the CA1 and CA3 regions $(\boldsymbol{g})$. The total volume encompassed by pyramidal neuron nuclei was determined from serial DAPI-stained sections. We find a $25 \%$ reduction in this volume ( $n=2$ animals for each group; volume was the average for both hippocampi of each animal). 


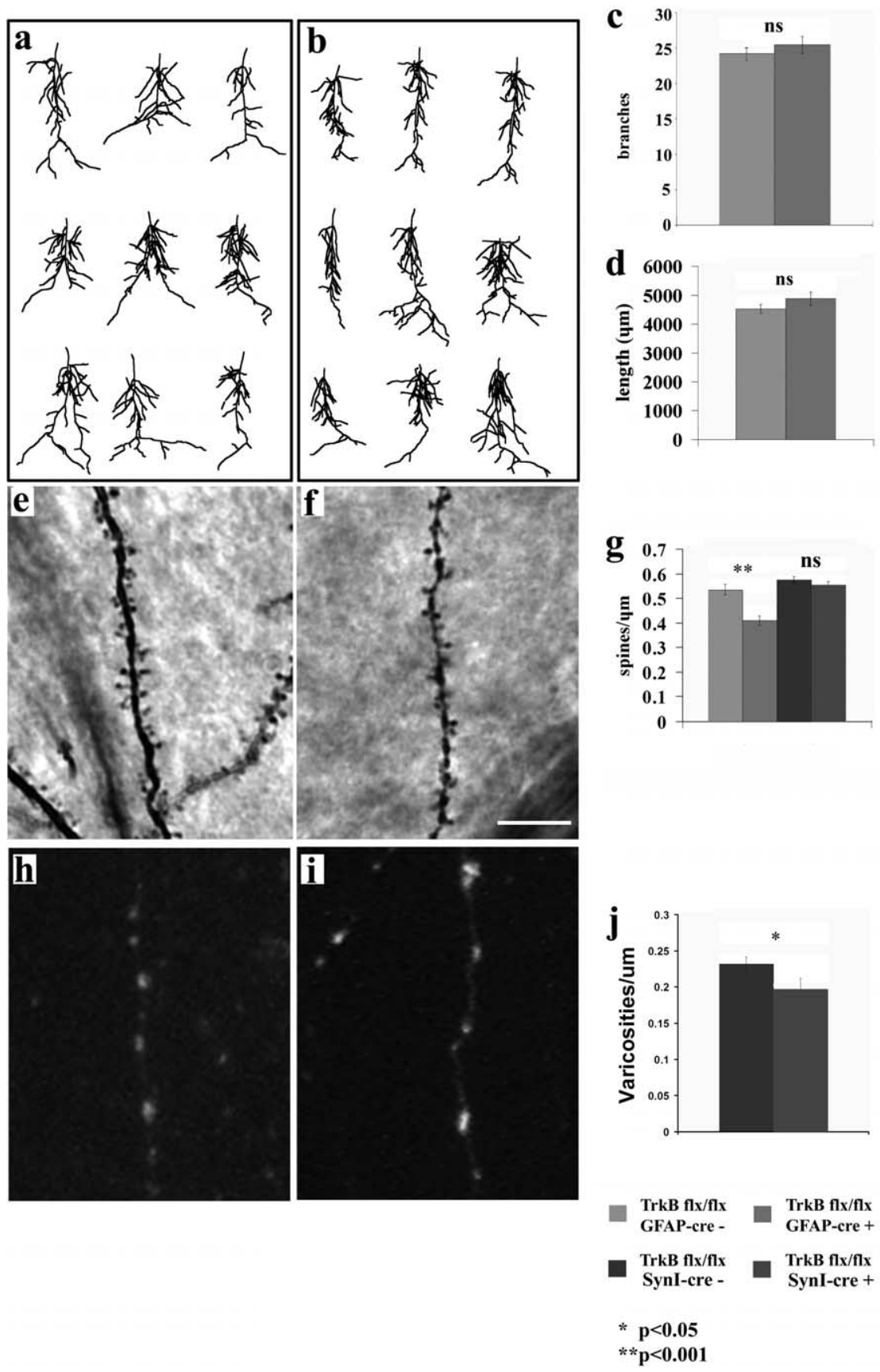

Figure 4. Decreased spine and axon varicosity density CA1 region of TrkB knock-out animals. Reconstructions of the apical dendritic arbor of TrkB flx/flx $\times$ Thy1-GFP-M (a) and TrkB flx/flx $\times$ hGFAP-cre $\times$ Thy1-GFP-M (b) pyramidal neurons are shown. The number of branch points and total dendritic arborization were calculated $(\boldsymbol{c}, \boldsymbol{d})$, revealing no change in knock-out versus control animals ( $p>0.2$ using two-tailed two-sample equal variance $t$ test; $n=27$ neurons from 3 mice and $n=21$ neurons from 2 mice, respectively). Spine density of CA1 zona radiatum dendrites was determined from Golgi-stained sections of control $(\boldsymbol{e})$, TrkB flx $/ f \mathrm{~lx} \times \mathrm{hGFAP-cre}(\boldsymbol{f})$, and TrkB flx/flx $\times$ synapsinl-cre animals. We found that TrkB flx/flx $\times$ hGFAP-cre animals have a significant reduction in spine density that is not observed in TrkB flx/flx $\times$ synapsinl-cre animals ( $g$; using two-tailed twosample equal variance $t$ test; $n=31$ dendritic segments from 22 neurons of 3 hGFAP littermate control mice; $n=33$ dendritic segments from 26 neurons of 3 TrkB flx/flx $\times$ hGFAP-cre mice; $n=74$ dendritic segments from 62 neurons of 4 synapsinl littermate controls; $n=77$ dendritic segments from 58 neurons of 4 TrkB flx/flx $\times$ syanpsinl-cre). Schaffer collateral axons traced using Alexa 488-conjugated dextran amine in control $(\boldsymbol{h})$ versus TrkB flx/flx $\times$ synapsinl-cre (i) mice indicate that presynaptic deletion of TrkB results in axons with a decreased density of varicosities ( $j$; using two-tailed two-sample equal variance $t$ test; $n=$ 18 axon segments from 2 mice and $n=16$ axon segments from 2 mice, respectively). Scale bar, $10 \mu \mathrm{m}$.

morphology in these neuronal populations (Fig. 3a,b). However, this mouse provides a poor model to study the effects of $\operatorname{TrkB}$ on these interneuronal populations attributable to the low levels of cre expression. Calbindin staining in knockout animals versus controls revealed no changes in the organization of the mossy fiber pathway (Fig. 3c,d). Last, to determine whether pyramidal neuron survival was affected in TrkB knock-out animals, the number of DAPI-stained nuclei in the pyramidal cell layer of the CA1 and CA3 regions was counted within a $40,000 \mu \mathrm{m}^{2}$ anatomically equivalent region (Fig. $3 e-g$ ). We found no significant difference in the average number of CA1 or CA3 neurons in knock-outs versus controls. Whereas the density of the pyramidal neurons was unaltered, it appeared that the length of the pyramidal cell layer was decreased in individual sections. To quantitate this difference, we calculated the total volume of the pyramidal cell layer from serial sections. We found that this volume was reduced by $25 \%$ in $\operatorname{TrkB} \times$ GFAP-cre knock-out animals (Fig. 3h). Additionally, we noted a qualitatively more significant decrease in the size of the dentate gyrus (Fig. 3).

\section{Decreased dendritic spine and axon varicosity density in TrkB knock-out pyramidal neurons}

TrkB and BDNF have been reported to exert effects on dendritic arborization. Mice harboring a GFP reporter gene under control of the GFP promoter [Thyl-GFP line $\mathrm{M}$ (Feng et al., 2000)] provide a means to examine the detailed structure of neurons in vivo. Thyl-GFP line $\mathrm{M}$ mice were crossed to TrkB flx/flx $\times$ hGFAP-cre mice, and reconstructions of the apical dendritic arbor were made from image stacks acquired as confocal z-series (Fig. $4 a, b$ ). We found no significant change in the total dendritic arborization of control (4524 \pm $158 \mu \mathrm{m})$ versus knock-out (4879 \pm 241 $\mu \mathrm{m}$ ) mice (Fig. $4 d$ ). To further assess arborization, we counted the number of dendritic branches. Again, we found no significant difference between control and knock-out animals (Fig. 4c).

To more closely examine the quality of the dendritic arbors in control versus mutant mice, we estimated the density of dendritic spines within the area CA1 stratum radiatum. Image stacks from $\mathrm{z}$-series of Golgi-stained tissues were acquired, and the density of dendritic spines was calcu-

Map2, neurofilament NF200, and GFAP (data not shown). hGFAP-cre is weakly expressed in GABAergic neurons, including a minority of parvalbumin- and calbindin-positive interneurons (Malatesta et al., 2003). We observed no alterations in number or lated. Control animals were found to have $0.535 \pm 0.023$ versus $0.410 \pm 0.019$ spines $/ \mu \mathrm{m}$ in TrkB $\times$ hGFAP-cre knock-out animals (Fig. $4 e-g)(p<0.0008$ using two-tailed two-sample equal variance $t$ test; $n=31$ dendritic segments from 22 neurons of 3 
mice and $n=33$ dendritic segments from 26 neurons of 3 mice, respectively).

The effect on spine density of CA1 neurons could be secondary to a change in the presynaptic inputs onto those cells. To test this plausible non-autonomous mechanism, we counted the spine density from TrkB $\times$ synapsinI-cre knock-out animals. We found no appreciable difference (Fig. $4 g$ ). This shows that the deletion of TrkB from the presynaptic cell alone (synapsinIcre) is incapable of producing the decrease in spine density seen when TrkB is deleted from both the presynaptic and postsynaptic neurons (hGFAP-cre).

To examine effects of presynaptic TrkB knock-out (synapsinI-cre) on axonal characteristics of the Schaffer collateral, we injected the axonal tracer Alexa dextran amine into the $\mathrm{CA} 3$ region of hippocampal slice cultures. Confocal images allowed visualization of axon varicosities within the stratum radiatum of area CA1. We found that, in control mice, the average axonal intervaricosity distance was $4.45 \pm 0.89$ $\mu \mathrm{m}$ (Fig. 4j). This distance was significantly increased to $6.11 \pm 1.63 \mu \mathrm{m}$ in the TrkB $\times$ synapsinI-cre knock-out animals (Fig. 4j) ( $p<0.022$ ). Thus, the density of axonal varicosities projecting to CA1 pyramidal neurons was significantly decreased, whereas the dendritic spine density of the CA1 neurons was unchanged in the TrkB $\times$ synapsinI-cre mice.

We also examined the effect of $\operatorname{TrkB}$ deletion on dendritic spine formation in TrkB $\times$ CaMKII-cre animals and found no decrease in spine density (supplemental Fig. $1 c$, available at www.jneurosci.org as supplemental material).

\section{The density of Schaffer collateral synapses is decreased in TrkB mutant mice}

Dendritic spines are the sites for the majority of excitatory synaptic terminals. To further analyze the effects of different patterns of TrkB deletion on synapse formation, we performed a quantitative analysis of synaptic puncta density in the hippocampal area CA1 stratum radiatum in the different $\operatorname{TrkB}$ conditional mutant mice. Antibodies to synaptophysin and PSD-95 were used to visualize both the presynaptic and postsynaptic specializations of the Schaffer collateral synapse (Fukaya and Watanabe, 2000). Immunostains were imaged on a laser scanning confocal microscope using a $100 \times$ objective and a $3 \times$ electronic zoom so that individual puncta could be resolved and quantified (Fig. 5). In control mice, we counted $1.087 \pm 0.040$ PSD-95 puncta/ $\mu \mathrm{m}^{2}$ and $1.006 \pm 0.039$ synaptophysin puncta/ $\mu \mathrm{m}^{2}$ (Fig. $5 a, b, m, n)$. There was no significant difference in this number
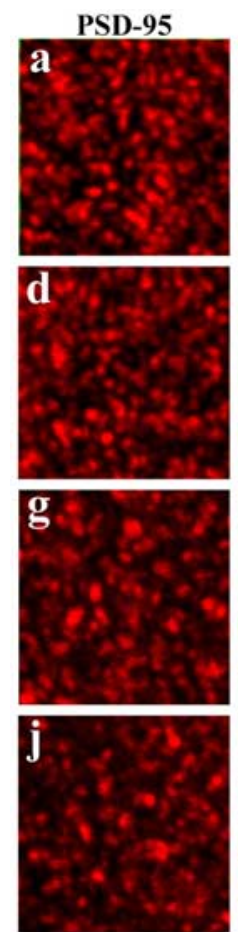

0
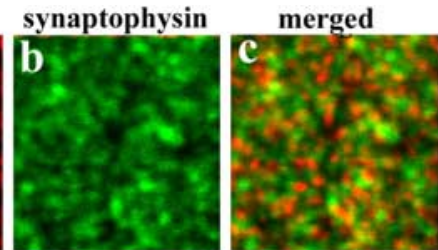

m
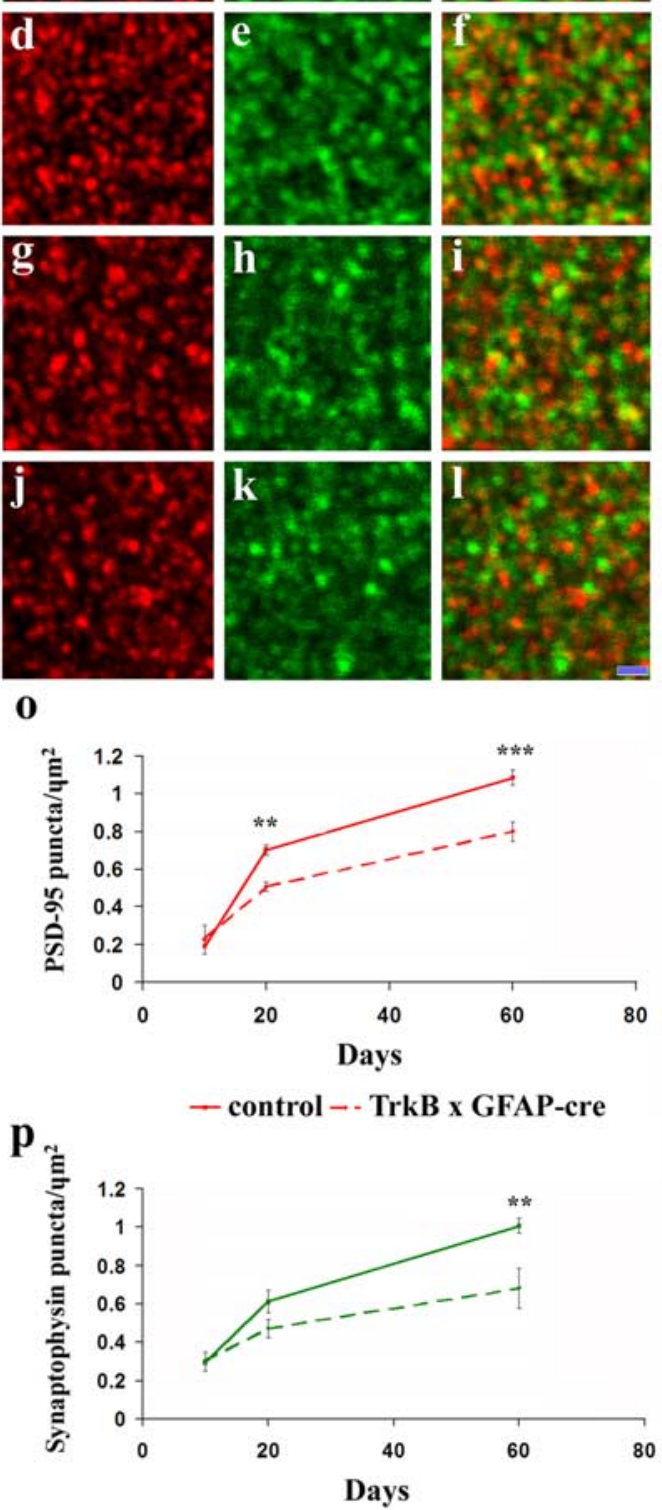

- control -- TrkB x GFAP-cre

Figure 5. Decreased synaptic density in TrkB knock-out animals. PSD-95 (red) and synaptophysin (green) antibodies were used to stain synapses in the stratum radiatum of hippocampal area CA1. There was no significant difference in the density of presynaptic or postsynaptic puncta in TrkB flx/flx $\times$ CaMKII-cre animals $(\boldsymbol{d}-\boldsymbol{f})$ when compared with control animals $(\boldsymbol{a}-\boldsymbol{c})$. In TrkB flx/flx $\times$ synapsinl-cre knock-out animals, there was no significant reduction in the density of PSD-95 puncta $(\boldsymbol{g})$ but a reduction in the number of detectable synaptophysin puncta $(\boldsymbol{h})$. TrkB flx/flx $\times$ hGFAP-cre knock-out animals have a significant reduction in the density of both PSD-95 (j) and synaptophysin ( $(\boldsymbol{k})$-positive puncta. Quantitative data for control [wild-type (WT)], TrkB flx/flx $\times$ CaMKII-cre (TCK), TrkB flx/flx $\times$ synapsinl-cre (TS), and TrkB flx/flx $\times$ hGFAP-cre (TG) animals are shown graphically for PSD-95 $(\boldsymbol{m})$ and synaptophysin $(\boldsymbol{n})$. The reduction in synaptic density observed in the TrkB flx/flx $\times$ hGFAP-cre animals is not observed at $\mathrm{P} 10$ and starts to become apparent by $\mathrm{P} 20(\boldsymbol{o}, \boldsymbol{p})$. Scale bar, $1 \mu \mathrm{m}$.

between wild-type littermate controls of the different mutant groups. In agreement with data on spine density, $\operatorname{TrkB} \mathrm{flx} / \mathrm{fl} x$ CaMKII-cre mice showed no significant reduction in the number of PSD-95 (1.017 \pm 0.059 puncta/ $\left.\mu \mathrm{m}^{2}\right)$ or synaptophysin $\left(0.930 \pm 0.081 \mathrm{puncta} / \mu \mathrm{m}^{2}\right)$-positive puncta (Fig. $\left.5 d, e, m, n\right)$. 

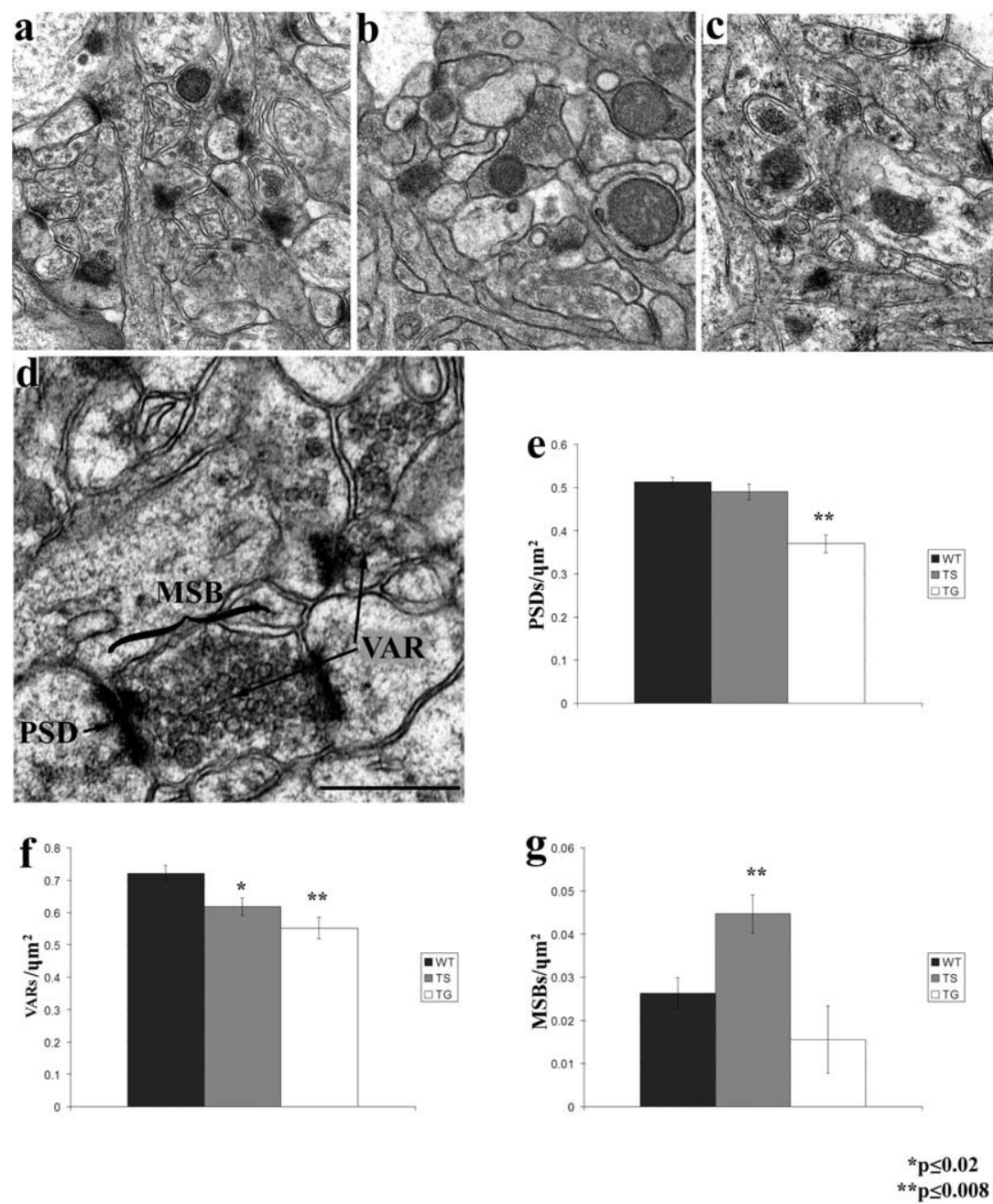

Figure 6. Synapse number and morphology is altered at the ultrastructural level. A representative electron micrograph from the CA1 stratum radiatum of wild-type $(\boldsymbol{a})$, TrkB flx/flx $\times$ synapsinl-cre $(\boldsymbol{b})$, and TrkB flx/flx $\times$ hGFAP-cre $(\boldsymbol{c})$ animals. A micrograph demonstrating those synaptic elements quantified in control [wild-type (WT)], TrkB flx/flx $\times$ synapsinl-cre (TS), and TrkB flx/flx $\times$ hGFAP-cre (TG) knock-out animals is shown in $\boldsymbol{d}$. The density of PSDs was decreased only when TrkB was knocked out both presynaptically and postsynaptically in the TG knock-out animals (e). The density of VARs is decreased only in the presynaptic (TS) and the presynaptic and postsynaptic (TG) knock-outs $(\boldsymbol{f})$. In the presynaptic TrkB flx/flx $\times$ synapsinl-cre knock-out, the disparity between the densities of presynaptic versus postsynaptic elements is attributable to the increased usage of a limited number of presynaptic terminals by postsynaptic densities. The increased density of MSBs in these mice reflects this increased usage ( $\boldsymbol{g} ; p$ value using two-tailed two-sample equal variance $t$ test; $n=4$ sections from 2 TrkB $\times$ synapsinl-cre mice, 5 sections from 2 TrkB $\times$ hGFAP-cre mice, and 8 sections from 4 control mice). Scale bars, $500 \mathrm{~nm}$.

Furthermore, no change in the number of presynaptic or postsynaptic terminals was observed in TrkB $\times$ CaMKII-cre animals that had been aged for 1 year (supplemental Fig. $1 d$, available at www.jneurosci.org as supplemental material). Thus, postnatal loss of TrkB after synapse formation (CaMKII-cre) had no detectable consequences on the density of presynaptic and postsynaptic terminals.

$\operatorname{TrkB} \mathrm{fl} / \mathrm{flx} \times$ synapsinI-cre animals displayed no significant reduction in the number of postsynaptic puncta $(0.936 \pm 0.082$ puncta $\left./ \mu \mathrm{m}^{2}\right)$. However, examination of presynaptic puncta revealed a significant reduction $\left(0.796 \pm 0.060 \mathrm{puncta} / \mu \mathrm{m}^{2} ; p<0.02\right.$; 20.9\%) (Fig. 5g,h,m,n). Finally, TrkB flx/flx $\times$ hGFAP-cre animals exhibited a significant reduction in the number of PSD-95-positive puncta $\left(0.801 \pm 0.052\right.$ puncta $\left./ \mu \mathrm{m}^{2} ; p<0.002 ; 26.3 \%\right)$ and also of presynaptic puncta $\left(0.682 \pm 0.103\right.$ puncta $\left./ \mu \mathrm{m}^{2} ; p<0.006 ; 32.2 \%\right)$ (Fig. $5 j, k, m, n$ ). In addition to quantifying the PSD-95- and synaptophysin-positive puncta, we counted yellow puncta representing the interface of synaptophysin and PSD-95. Optical sections of $0.8 \mu \mathrm{m}$ thick were used to resolve individual puncta; therefore, not all puncta are seen apposed to out-of-plane presynaptic/postsynaptic partners. The trend found for colocalization was the same as that seen for the PSD-95 puncta (control, $0.983 \pm 0.126 \mathrm{puncta} / \mu \mathrm{m}^{2} ; \operatorname{TrkB} \mathrm{flx} / \mathrm{flx} \times$ CaMKII-cre, $0.879 \pm 0.140$ puncta/um2; TrkB flx/flx $\times$ synapsinI-cre, $0.856 \pm 0.152$ puncta/ $\mu \mathrm{m} 2$; TrkB flx/flx $\times$ hGFAP-cre, $0.615 \pm 0.109$ puncta $/ \mu \mathrm{m} 2$; mean $\pm \mathrm{SD})$. Thus, there are fewer presynaptic terminals present in the $\operatorname{TrkB} \mathrm{flx} / \mathrm{flx} \times$ synapsinI-cre mice but similar numbers of synaptic junctions when compared with control mice. In TrkB flx/flx $\times$ hGFAP-cre mice, we found fewer presynaptic and postsynaptic puncta, as well as fewer synaptic junctions.

To determine the timing over which the synaptic phenotype develops, we examined synaptic density in $\operatorname{TrkB}$ flx/flx $X$ hGFAP-cre mice earlier in development (Fig. 5o,p). At P10, we found no significant difference in the density of synaptic puncta between control and knock-out animals. By P20, the difference became significant for PSD-95 puncta $(0.703 \pm 0.028$ vs $\left.0.507 \pm 0.025 \mathrm{puncta} / \mu \mathrm{m}^{2} ; p<0.003\right)$ and approached significance for synaptophysin puncta $(0.613 \pm 0.060$ vs $0.471 \pm$ 0.048 puncta $\left./ \mu \mathrm{m}^{2} ; p<0.088\right)$. Thus, although the decrease in synaptic density becomes apparent between P10 and P20, it is the consequence of early developmental loss (hGFAP and synapsinI) and not of acute loss of TrkB after this developmental period (CaMKII).

\section{Presynaptic role of TrkB in remodeling of synaptic boutons}

The immunohistochemical assessment of synaptic density was extended to the ultrastructural level in TrkB $\times$ synapsinI-cre and TrkB $\times$ hGFAP-cre animals. The density of asymmetric PSDs, vesicle-containing VARs, and instances in which two or more PSDs from different spines interacted with a single VAR (MSBs) were examined (Fig. 6). In agreement with the immunohistochemical and spine density analyses, we observed a significant decrease in the density of PSDs in TrkB $\times$ hGFAP-cre $\left(0.37 \pm 0.041\right.$ PSDs $\left./ \mu \mathrm{m}^{2} ; p<0.0001\right)$ mice and no change in this density in $\operatorname{TrkB} \times$ synapsinI-cre $(0.49 \pm 0.040$ PSDs $\left./ \mu \mathrm{m}^{2} ; p>0.32\right)$ mice when compared with control mice $\left(0.51 \pm 0.35\right.$ PSDs $\left./ \mu \mathrm{m}^{2}\right)$ (Fig. $6 e$ ). We also found a decrease in the density of varicosities in both TrkB $\times$ synapsinI-cre $(0.62 \pm 0.061$ VARs $\left./ \mu \mathrm{m}^{2}\right)$ and TrkB $\times$ hGFAP-cre $\left(0.55 \pm 0.067 \mathrm{VARs} / \mu \mathrm{m}^{2}\right)$ animals when compared with control $\left(0.72 \pm 0.07 \mathrm{VARs} / \mu \mathrm{m}^{2}\right)$ animals (Fig. $6 f$ ). In addition, the discrepancy between the density of presynaptic and postsynaptic elements in the TrkB $\times$ synapsinI-cre animals was resolved at the ultrastructural level as an increase in the density of MSBs (Fig. $6 g$ ) (control, $0.026 \pm 0.009$ vs TrkB flx/flx $\times$ synapsinI-cre, $\left.0.045 \pm 0.009 \mathrm{MSBs} / \mu \mathrm{m}^{2}\right)$. Therefore, we conclude that presynaptic deletion of TrkB in neurons of the Schaffer collat- 
eral results in a deficiency of those CA3 pyramidal neurons to remodel their axons in response to increasing interactions with postsynaptic elements.

\section{Cell-autonomous role for TrkB in the} formation of the postsynaptic specialization

The decrease in spines, PSD-95 puncta, and PSDs seen in the TrkB $\times$ hGFAP-cre animals may indicate a specific postsynaptic role for TrkB. However, hGFAP-cre is expressed in both glia and neurons. Thus, the postsynaptic deficits seen in these mice may also indicate a role for glial TrkB receptors or that presynaptic and postsynaptic deletion of TrkB may act synergistically. To further address the spatial requirements for TrkB signaling during the process of synapse formation, an in vitro system in which TrkB ablation can be manipulated in a spatially and temporally specific manner was used. Primary hippocampal cultures from TrkB flx/flx animals were prepared (see Materials and Methods). The time course of excitatory synapse formation in these cultures has been characterized previously (Kavalali et al., 1999). To delete TrkB from neurons before synapse formation, we used calcium phosphate to transfect 5 DIV hippocampal neurons with expression plasmids for GFP or GFP-cre. The low efficiency of transfection $(<1 \%)$ coupled with GFP expression allowed for examination of synapse populations for which TrkB is solely deleted in the postsynaptic cell. We next used electrophysiological and immunohistochemical methods to examine the form and function of synapses at 10 DIV in control versus TrkB knock-out neurons.

Whole-cell patch-clamp recording was used to compare miniature EPSCs (mEP-

SCs) in TrkB knock-out cells with those of controls (Fig. 7). We found a significant decrease in the frequency of mEPSCs in TrkB knock-out cells (GFP-cre transfected) versus GFP transfected control cells $(0.09 \pm 0.03$ vs $0.38 \pm 0.08 \mathrm{~Hz}$ respectively; $p<0.01$; $n=7$ for both groups) (Fig. $7 b$ ). We saw no difference in the frequency of synaptic events between nontransfected and GFPtransfected cells or in cre-expressing wild-type neurons. When we examined the amplitude of the isolated mEPSCs, we found no significant difference in control versus knock-out cells (Fig. 7c). Because the observed difference in mEPSC frequency was attributable to a postsynaptic genetic manipulation, we tested the response to exogenously applied glutamate. The amplitude of response to exogenously applied glutamate was reduced in the TrkB knock-out cells (Fig. 7) (1.41 \pm 0.04 vs $0.24 \pm 0.01 \mathrm{nA} ; n=$ 7 for both groups; $p<0.02$ ). Thus, postsynaptic deletion of TrkB resulted in decreased postsynaptic responsiveness to exogenous glutamate, decreased mEPSC frequency, and no change in the mEPSC amplitude. These data are consistent with the interpretation that the TrkB knock-out cells have fewer functional postsyn- aptic sites; however, the strength of those synapses that persist is not significantly altered when compared with control neurons.

Immunohistochemical analysis of the synapses in TrkB knock-out neurons (Fig. 8) confirms a specific change in postsynapse formation. Numerous synaptophysin-positive synaptic inputs from the surrounding nontransfected neurons onto both control and knock-out neurons were noted. However, in knockout neurons, the number of postsynaptic PSD-95-positive puncta apposed to presynaptic inputs is greatly reduced when compared with controls (Fig. 8b,d,f). Quantitative analysis indicates a $63 \%$ decrease in synaptophysin-positive puncta apposed to PSD-95-positive puncta $(89.2 \pm 5.2 \%$ control vs $26.7 \pm 11.6 \%$ in TrkB knock-out neurons) (Fig. $8 g$ ). This is attributable to a $66 \%$ decrease in the number of PSD-95-positive puncta in knock-out neurons compared with control neurons (Fig. 8h). Although there were a large number of presynaptic inputs onto the TrkB knock-out neurons, these neurons appeared deficient in the formation of postsynaptic machinery in response to those inputs. From these studies, we conclude that TrkB loss in neurons 


\section{GFP}
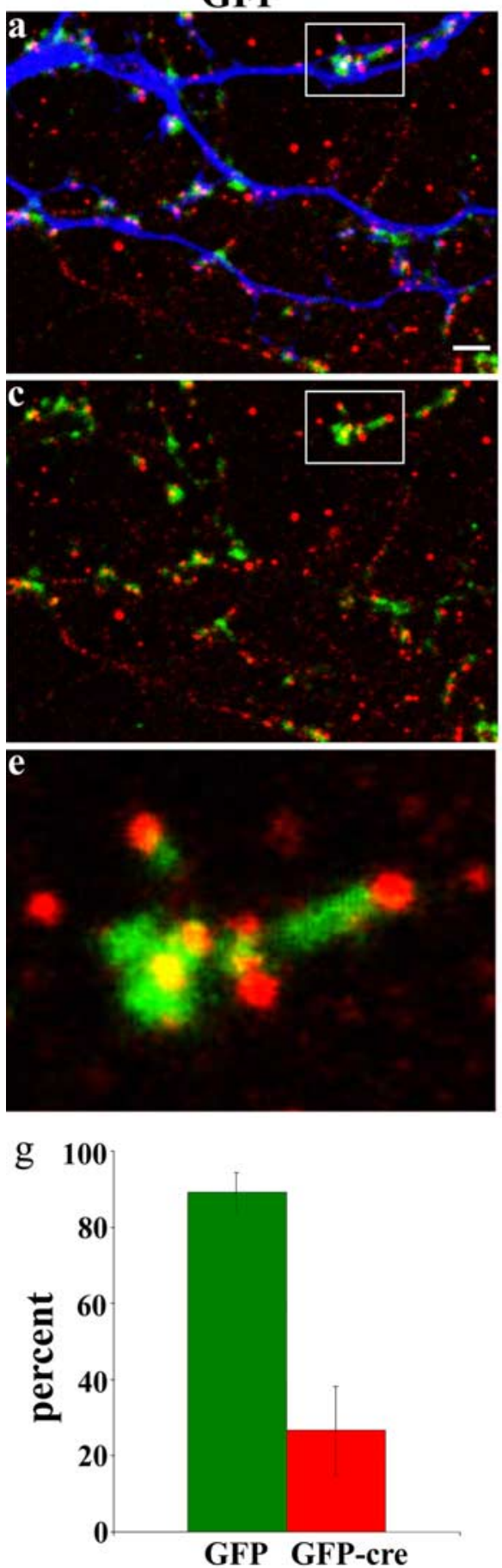
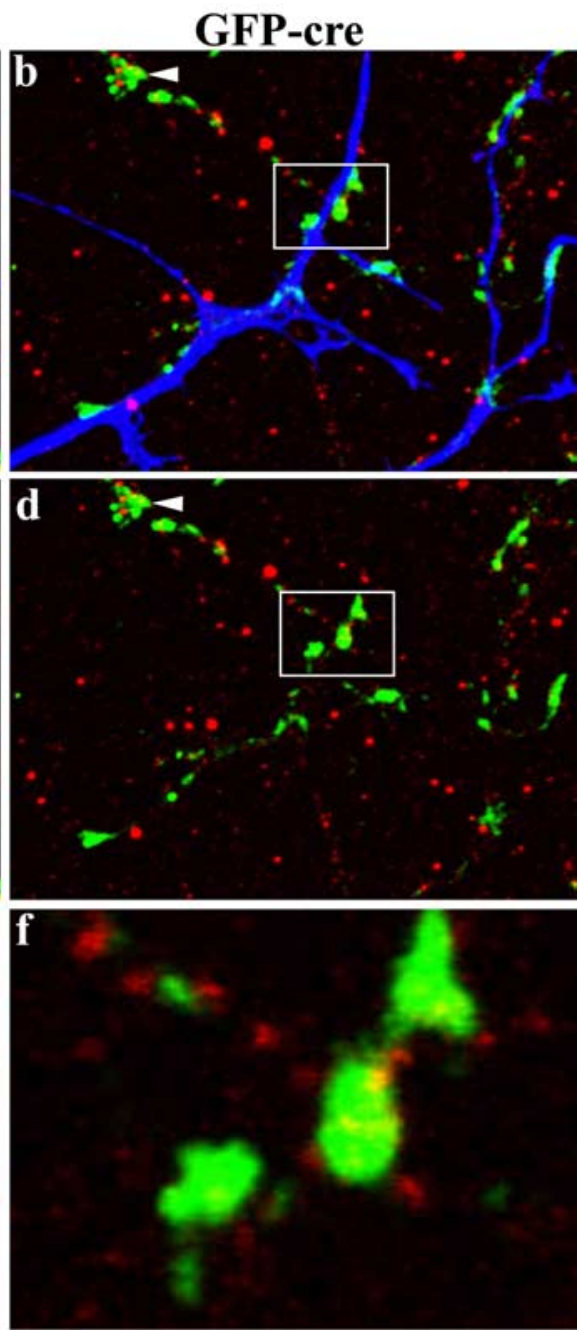

$\mathrm{h}$

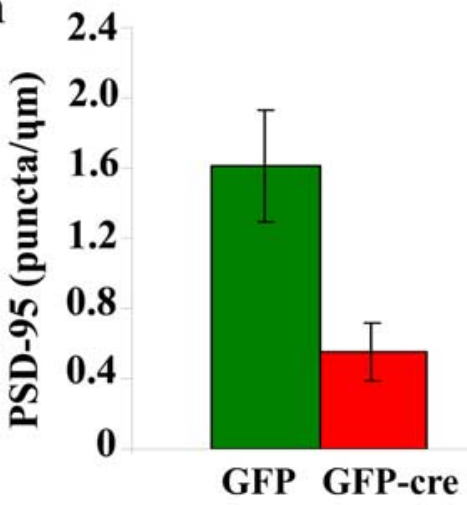

Figure 8. Altered synapse formation attributable to specific postsynaptic ablation of TrkB in hippocampal neurons. Dissociated hippocampal neurons were transfected with GFP (blue neuron in $\boldsymbol{a}$ ) or GFP-cre (blue neuron in $\boldsymbol{b}$ ) to produce control and TrkB knock-out neurons, respectively. Immunohistochemical staining of synapses from TrkB knock-out (b) versus GFP control (a) neurons reveals altered postsynaptic density formation. Synaptophysin puncta (green) from the surrounding nontransfected neurons form onto both the control and TrkB knock-out neurons. In images of $\boldsymbol{a}$ and $\boldsymbol{b}$ with the blue channel removed, PSD-95 (red) staining reveals normal postsynaptic densities apposed to the synaptophysin-positive puncta in the GFP-transfected control cell (c). Postsynaptic deletion of TrkB results in decreased PSD-95-positive puncta $(\boldsymbol{d})$ apposed to the synaptophysin-positive presynaptic inputs from surrounding nontransfected neurons. $\boldsymbol{e}, \boldsymbol{f}$, High-magnification images of the boxes in $\boldsymbol{c}$ and $\boldsymbol{d}$ reveal altered PSD-95 staining in TrkB knock-out neurons. Synapses that formed between nontransfected control cells on the same coverslip as the TrkB knock-out neurons appear to have normal PSD-95 staining (arrow in $\boldsymbol{d}$ ). The percentage of synaptophysin puncta apposed to PSD-95 puncta was quantified in GFP-versus GFP-cre-transfected neurons $(\boldsymbol{g} ; n=7$ neurons for each group; $p<1.9 \times 10^{-8}$ using two-tailed $t$ test). The total density of PSD-95-positive puncta was also reduced in knock-out versus control neurons ( $\boldsymbol{h} ; n=7$ neurons for each group; $p<0.01$ using two-tailed $t$ test). Scale bar, $5 \mu \mathrm{m}$.

before synapse formation impairs the normal development of the postsynaptic density via a cell-autonomous mechanism.

Decreased synaptic AMPA and NMDA receptor subunits in TrkB $\times$ hGFAP-cre animals

To better understand the molecular nature of the synapses missing in the TrkB flx/ flx $\times$ hGFAP-cre animals, we assessed the state of synaptic proteins from hippocampal preparations. Decreases in PDZ (PSD95/Discs large/zona occludens-1) domain containing proteins and glutamate receptor subunits have been demonstrated previously in knock-out animals (Carmona et al., 2003; Jourdi et al., 2003). Hippocampal presynaptic and postsynaptic membranes were isolated from TrkB flx/flx $\times$ hGFAPcre animals and used for quantitative Western blot analysis (Fig. 9a,b) (see Materials and Methods). As anticipated from preceding studies, a $27.23 \pm 13.23 \%(p<$ 0.04 ) decrease in synaptic PSD-95 was observed. The NMDA receptor subunits NR1 $(21.62 \pm 11.42 \% ; p<0.025)$ and NR2A $(23.11 \pm 14.71 \% ; p<0.02)$ were also decreased. However, there was no significant change in the developmental subunit NR2B ( $p>0.75)$. Additionally, we noted decreases in AMPA receptor subunits. There were decreases in GluR1 and GluR2/3 subunits of $27.60 \pm 6.71 \%(p<$ $0.002)$ and $14.76 \pm 3.34 \%(p<0.002)$, respectively, but we found no decrease in the AMPA receptor subunit GluR4 or the kainate receptor subunits GluR5 or GluR6/7.

To determine whether the change in synaptic protein expression was specific to the synaptic fraction or whether it reflected a more global change in synaptic protein levels, we examined the expression level from the whole-cell P1 fraction (Fig. $9 c, d)$. Here, consistent with the synaptic fraction data, we found that the levels of PSD-95, NR2A, and GluR1 were decreased and that NR2B was unchanged. Unlike the synaptic fraction, there was no decrease in the levels of NR1 or GluR2/3. From this result, we conclude that the loss of TrkB affects the expression of some synaptic components. This global loss of expression, in turn, may alter the localization of others.

\section{Discussion}

Early in development, many synapses are established in the absence of activity and activity-dependent release (Mammen et al., 1997; Verhage et al., 2000). At later developmental stages, synaptogenesis takes place under conditions of activity- 
dependent refinement of connectivity between neurons. It has been hypothesized that neurotrophins are important factors hoarded by those more competitively fit neurons to maintain and increase their synaptic territory (Katz and Shatz, 1996; Cabelli et al., 1997). One prediction of this hypothesis would be that neurotrophins and their receptors must affect synapse formation or neuronal outgrowth in a cellautonomous manner. Our results provide direct genetic evidence that the BDNF receptor TrkB does signal in a cellautonomous manner to promote excitatory synapse formation in Schaffer collaterals. Furthermore, we provide evidence that this effect is most pronounced during a period in which maturation of synaptic connectivity is occurring.

TrkB appears to have a role in the formation of both presynaptic and postsynaptic structures. In the presynaptic deletion of TrkB generated in $\operatorname{TrkB} \mathrm{flx} / \mathrm{flx} \times$ synapsinI-cre animals, specific deficits in presynaptic structures were found as assessed by decreased synaptophysinpositive puncta and axon varicosities. The CA1 neurons of these animals retained normal numbers of PSD-95-positive puncta, dendritic spines, and postsynaptic densities. The decrease in presynaptic structures with no change in the number of postsynaptic structures was accompanied by an increased incidence of multisynapse boutons. We conclude from these data that TrkB plays a cell-autonomous role in the remodeling of presynaptic structure at the Schaffer collaterals. When TrkB is deleted at both presynaptic and postsynaptic sites during early neurogenesis (TrkB flx/flx $\times$ hGFAP-cre), the combined loss results in an added reduction of CA1 postsynaptic puncta and dendritic spines, in addition to the reduction of presynaptic elements seen in the synapsinI-cre recombined animals. The difference in phenotype between these two animals could indicate a cellautonomous role for TrkB at both synaptic terminals. In primary neuronal cultures with TrkB deleted only in the postsynaptic neuron, a reduction in electrophysiological responses and in PSD-95-positive puncta occurs. These results together indicate that TrkB does have a cell-autonomous role in excitatory synapse formation.

The effects of TrkB on synapse formation appear to be most salient in environments in which activity-dependent remodeling of synaptic connectivity occurs. BDNF is transported to, and released from, both presynaptic and postsynaptic sites in an activity-dependent manner (von Bartheld et al., 1996; Haubensak et al., 1998; Hartmann et al., 2001; Kohara et al., 2001). Moreover, BDNF and TrkB expression are regulated by activity (Zafra et al., 1990; Patterson et al., 1992). In the cat, expression is regulated during the critical period (Cabelli et al., 1996; Lein and Shatz, 2000; Lein et al., 2000). Furthermore, cortical injection of TrkB-IgG results in an inability of ocular dominance columns to segregate (Cabelli et al., 1997). In our study, the in vivo onset of synaptic puncta loss (between P10 and P20) and the molecular composition of those synapses lost imply that TrkB is necessary c whole-cell fraction
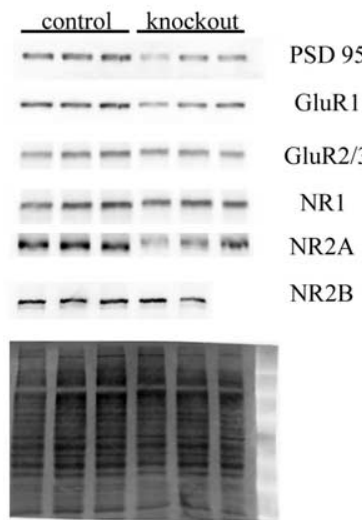

d

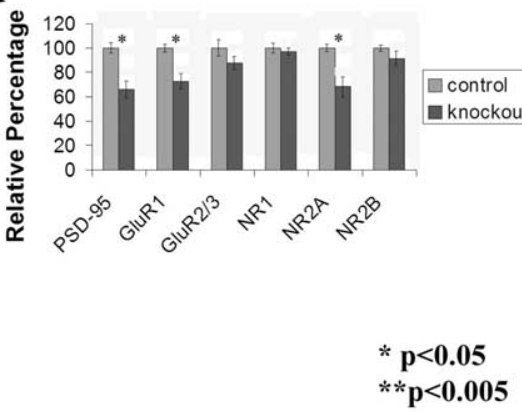

Figure 9. Decreased expression of synaptic proteins. Protein from TrkB $\times$ hGFAP-cre knock-out animals was isolated by reduction in the expression of PSD-95, GluR1, and NR2A was noted $(\boldsymbol{c}, \boldsymbol{d})$. However, there was no reduction seen in GluR2/3, NR1, or NR2B $(\boldsymbol{c}, \boldsymbol{d})$. Sypro Ruby stain was used to stain total protein as a quantitative loading control $(\boldsymbol{a}, \boldsymbol{c})$.

for synapse formation during activity-dependent refinement of synaptic connectivity. The time course of AMPA and NMDA receptor subunit expression supports this. Relative to the other subunits, GluR4 and NR2B expression is highest just after birth and is reduced thereafter (Zhu et al., 2000). The GluR1, GluR2/3, and NR2A subunits have increasing synaptic expression over the first 5 weeks of postnatal development (Petralia et al., 1999; Sans et al., 2000). In the present study, at P60, we noted a decrease in all of the subunits (GluR1, GluR2/3, NR1, and NR2A) that display increasing levels of expression during the late developmental period and no effect on receptor subunit levels (GluR4 and NR2B), with constant or decreasing expression over this period. Thus, the loss of TrkB results in decreased synaptic molecules as well as in those structures (varicosities and spines) associated with synapses.

It is surprising that no changes in dendritic arborization were observed in this study. That the effect was limited to the level of the spine and varicosity supports the notion that the physiological range of the growth promoting activity of BDNF is spatially limited in vivo (Horch and Katz, 2002). Furthermore, we demonstrate that the effect of TrkB is cell autonomous and that this effect is expressed at both presynaptic and postsynaptic sites. Together, these data support the notion that TrkB plays a role in the activity-dependent morphogenesis of both presynaptic and postsynaptic structures in vivo. It is possible that, in older animals, these morphological changes will be compounded and that $\operatorname{TrkB} \mathrm{flx} / \mathrm{flx} \times$ GFAP-cre animals will display more striking changes in dendritic arborization. 
In the postdevelopmental presynaptic and postsynaptic deletion of TrkB (TrkB flx/flx $\times$ CaMKII-cre mice), we observed no deficits in synaptic density. Thus, it appears that TrkB loss was not associated with disassembly of existing synapses. The interpretation of this result is limited because of the mosaic expression of cre in this mouse. However, our confidence in this interpretation is increased by three facts: cre appears to efficiently recombine all floxed alleles in cells in which it is expressed, there does not appear to be compensation for lost synapses in knock-out cells by wild-type cells, and no deficit in synapse number appears at up to 1 year of age in these animals (supplemental Fig. 1, available at www.jneurosci.org as supplemental material). From none of these data can we conclude that the deletion of TrkB in the adult has no change on synapse formation. It is thought that there is synaptic turnover in the adult (Trachtenberg et al., 2002; Muller and Nikonenko, 2003). However, net changes in synapse number in adult animals have been observed only in specialized situations, such as the estrous cycle, associative learning, and LTP (Andersen and Soleng, 1998; Woolley, 1999). If the role for TrkB is equivalent in the adult to that observed for the developmental ablations caused by the other cre transgenes, one might expect attenuation of synapse loss rather than the observed wild-type equivalence. One possible explanation for this equivalence is that the mechanism underlying synaptic turnover in the postnatal animal is different from the TrkB-dependent mechanism in development. Alternatively, more subtle effects of TrkB deletion on synapse formation in the adult may be observable only when net changes in synapse number can be elicited or the dynamics of synapse formation over time observed. These possibilities remain to be tested using more sophisticated methods.

During development, there are dramatic punctuated changes in synapse number as activity-dependent refinement of synapses occurs to allow for acquisition of those abilities that are necessary for a viable organism. Later in life, these changes become subtle and slow. However, it is the perseverance of this ability to change that allows for learning and behavioral modification that can dramatically improve the fitness of that organism. Our results indicate that the activation of TrkB plays direct and vital roles during developmental synapse formation. These studies do not address additional roles for $\operatorname{TrkB}$ in the synaptically dynamic adult brain, in which it is possible that $\operatorname{TrkB}$ maintains a role in synapse formation that is important for the long-term expression of plastic changes.

\section{References}

Aguado F, Carmona MA, Pozas E, Aguilo A, Martinez-Guijarro FJ, Alcantara S, Borrell V, Yuste R, Ibanez CF, Soriano E (2003) BDNF regulates spontaneous correlated activity at early developmental stages by increasing synaptogenesis and expression of the $\mathrm{K}^{+} / \mathrm{Cl}^{-}$co-transporter KCC2. Development 130:1267-1280.

Alsina B, Vu T, Cohen-Cory S (2001) Visualizing synapse formation in arborizing optic axons in vivo: dynamics and modulation by BDNF. Nat Neurosci 4:1093-1101.

Andersen P, Soleng AF (1998) Long-term potentiation and spatial training are both associated with the generation of new excitatory synapses. Brain Res Brain Res Rev 26:353-359.

Biederer T, Sara Y, Mozhayeva M, Atasoy D, Liu X, Kavalali ET, Sudhof TC (2002) SynCAM, a synaptic adhesion molecule that drives synapse assembly. Science 297:1525-1531.

Bozdagi O, Shan W, Tanaka H, Benson DL, Huntley GW (2000) Increasing numbers of synaptic puncta during late-phase LTP: N-cadherin is synthesized, recruited to synaptic sites, and required for potentiation. Neuron 28:245-259.

Cabelli RJ, Allendoerfer KL, Radeke MJ, Welcher AA, Feinstein SC, Shatz CJ (1996) Changing patterns of expression and subcellular localization of TrkB in the developing visual system. J Neurosci 16:7965-7980.
Cabelli RJ, Shelton DL, Segal RA, Shatz CJ (1997) Blockade of endogenous ligands of trkB inhibits formation of ocular dominance columns. Neuron 19:63-76.

Carmona MA, Martinez A, Soler A, Blasi J, Soriano E, Aguado F (2003) $\mathrm{Ca}^{2+}$-evoked synaptic transmission and neurotransmitter receptor levels are impaired in the forebrain of trkb $(-/-)$ mice. Mol Cell Neurosci 22:210-226.

Cohen-Cory S (2002) The developing synapse: construction and modulation of synaptic structures and circuits. Science 298:770-776.

Collin C, Vicario-Abejon C, Rubio ME, Wenthold RJ, McKay RD, Segal M (2001) Neurotrophins act at presynaptic terminals to activate synapses among cultured hippocampal neurons. Eur J Neurosci 13:1273-1282.

Dymecki SM (1996) Flp recombinase promotes site-specific DNA recombination in embryonic stem cells and transgenic mice. Proc Natl Acad Sci USA 93:6191-6196.

Feng G, Mellor RH, Bernstein M, Keller-Peck C, Nguyen QT, Wallace M, Nerbonne JM, Lichtman JW, Sanes JR (2000) Imaging neuronal subsets in transgenic mice expressing multiple spectral variants of GFP. Neuron 28:41-51.

Fukaya M, Watanabe M (2000) Improved immunohistochemical detection of postsynaptically located PSD-95/SAP90 protein family by protease section pretreatment: a study in the adult mouse brain. J Comp Neurol 426:572-586.

Gorski JA, Zeiler SR, Tamowski S, Jones KR (2003a) Brain-derived neurotrophic factor is required for the maintenance of cortical dendrites. J Neurosci 23:6856-6865.

Gorski JA, Balogh SA, Wehner JM, Jones KR (2003b) Learning deficits in forebrain-restricted brain-derived neurotrophic factor mutant mice. Neuroscience 121:341-354.

Hartmann M, Heumann R, Lessmann V (2001) Synaptic secretion of BDNF after high-frequency stimulation of glutamatergic synapses. EMBO J 20:5887-5897.

Haubensak W, Narz F, Heumann R, Lessmann V (1998) BDNF-GFP containing secretory granules are localized in the vicinity of synaptic junctions of cultured cortical neurons. J Cell Sci 111:1483-1493.

He XP, Kotloski R, Nef S, Luikart BW, Parada LF, McNamara JO (2004) Conditional deletion of TrkB but not BDNF prevents epileptogenesis in the kindling model. Neuron 43:31-42.

Horch HW, Katz LC (2002) BDNF release from single cells elicits local dendritic growth in nearby neurons. Nat Neurosci 5:1177-1184.

Jones KR, Farinas I, Backus C, Reichardt LF (1994) Targeted disruption of the BDNF gene perturbs brain and sensory neuron development but not motor neuron development. Cell 76:989-999.

Jourdain P, Nikonenko I, Alberi S, Muller D (2002) Remodeling of hippocampal synaptic networks by a brief anoxia-hypoglycemia. J Neurosci 22:3108-3116.

Jourdi H, Iwakura Y, Narisawa-Saito M, Ibaraki K, Xiong H, Watanabe M, Hayashi Y, Takei N, Nawa H (2003) Brain-derived neurotrophic factor signal enhances and maintains the expression of AMPA receptorassociated PDZ proteins in developing cortical neurons. Dev Biol 263:216-230.

Katz LC, Shatz CJ (1996) Synaptic activity and the construction of cortical circuits. Science 274:1133-1138.

Kavalali ET, Klingauf J, Tsien RW (1999) Activity-dependent regulation of synaptic clustering in a hippocampal culture system. Proc Natl Acad Sci USA 96:12893-12900.

Kernie SG, Liebl DJ, Parada LF (2000) BDNF regulates eating behavior and locomotor activity in mice. EMBO J 19:1290-1300.

Klein R, Smeyne RJ, Wurst W, Long LK, Auerbach BA, Joyner AL, Barbacid M (1993) Targeted disruption of the trkB neurotrophin receptor gene results in nervous system lesions and neonatal death. Cell 75:113-122.

Kohara K, Kitamura A, Morishima M, Tsumoto T (2001) Activitydependent transfer of brain-derived neurotrophic factor to postsynaptic neurons. Science 291:2419-2423.

Lein ES, Shatz CJ (2000) Rapid regulation of brain-derived neurotrophic factor mRNA within eye-specific circuits during ocular dominance column formation. J Neurosci 20:1470-1483.

Lein ES, Hohn A, Shatz CJ (2000) Dynamic regulation of BDNF and NT-3 expression during visual system development. J Comp Neurol 420:1-18.

Luikart BW, Nef S, Shipman T, Parada LF (2003) In vivo role of truncated trkb receptors during sensory ganglion neurogenesis. Neuroscience 117:847-858 
Malatesta P, Hack MA, Hartfuss E, Kettenmann H, Klinkert W, Kirchhoff F, Gotz M (2003) Neuronal or glial progeny: regional differences in radial glia fate. Neuron 37:751-764.

Mammen AL, Huganir RL, O’Brien RJ (1997) Redistribution and stabilization of cell surface glutamate receptors during synapse formation. J Neurosci 17:7351-7358.

Martinez A, Alcantara S, Borrell V, Del Rio JA, Blasi J, Otal R, Campos N, Boronat A, Barbacid M, Silos-Santiago I, Soriano E (1998) TrkB and TrkC signaling are required for maturation and synaptogenesis of hippocampal connections. J Neurosci 18:7336-7350.

Minichiello L, Klein R (1996) TrkB and TrkC neurotrophin receptors cooperate in promoting survival of hippocampal and cerebellar granule neurons. Genes Dev 10:2849-2858.

Minichiello L, Korte M, Wolfer D, Kuhn R, Unsicker K, Cestari V, RossiArnaud C, Lipp HP, Bonhoeffer T, Klein R (1999) Essential role for TrkB receptors in hippocampus-mediated learning. Neuron 24:401-414.

Muller D, Nikonenko I (2003) Dynamic presynaptic varicosities: a role in activity-dependent synaptogenesis. Trends Neurosci 26:573-575.

Patterson SL, Grover LM, Schwartzkroin PA, Bothwell M (1992) Neurotrophin expression in rat hippocampal slices: a stimulus paradigm inducing LTP in CA1 evokes increases in BDNF and NT-3 mRNAs. Neuron 9:1081-1088.

Petralia RS, Esteban JA, Wang YX, Partridge JG, Zhao HM, Wenthold RJ, Malinow R (1999) Selective acquisition of AMPA receptors over postnatal development suggests a molecular basis for silent synapses. Nat Neurosci 2:31-36.

Poo MM (2001) Neurotrophins as synaptic modulators. Nat Rev Neurosci 2:24-32.

Rico B, Xu B, Reichardt LF (2002) TrkB receptor signaling is required for establishment of GABAergic synapses in the cerebellum. Nat Neurosci 5:225-233.

Sans N, Petralia RS, Wang YX, Blahos II J, Hell JW, Wenthold RJ (2000) A developmental change in NMDA receptor-associated proteins at hippocampal synapses. J Neurosci 20:1260-1271.

Sorra KE, Harris KM (1993) Occurrence and three-dimensional structure of multiple synapses between individual radiatum axons and their target pyramidal cells in hippocampal area CA1. J Neurosci 13:3736-3748.

Trachtenberg JT, Chen BE, Knott GW, Feng G, Sanes JR, Welker E, Svoboda
K (2002) Long-term in vivo imaging of experience-dependent synaptic plasticity in adult cortex. Nature 420:788-794

Tsien JZ, Chen DF, Gerber D, Tom C, Mercer EH, Anderson DJ, Mayford M, Kandel ER, Tonegawa S (1996) Subregion- and cell type-restricted gene knockout in mouse brain. Cell 87:1317-1326.

Verhage M, Maia AS, Plomp JJ, Brussaard AB, Heeroma JH, Vermeer H, Toonen RF, Hammer RE, van den Berg TK, Missler M, Geuze HJ, Sudhof TC (2000) Synaptic assembly of the brain in the absence of neurotransmitter secretion. Science 287:864-869

Vicario-Abejon C, Collin C, McKay RD, Segal M (1998) Neurotrophins in duce formation of functional excitatory and inhibitory synapses between cultured hippocampal neurons. J Neurosci 18:7256-7271.

von Bartheld CS, Byers MR, Williams R, Bothwell M (1996) Anterograde transport of neurotrophins and axodendritic transfer in the developing visual system. Nature 379:830-833.

Woolley CS (1999) Effects of estrogen in the CNS. Curr Opin Neurobio 9:349-354.

Xu B, Gottschalk W, Chow A, Wilson RI, Schnell E, Zang K, Wang D, Nicoll RA, Lu B, Reichardt LF (2000) The role of brain-derived neurotrophic factor receptors in the mature hippocampus: modulation of long-term potentiation through a presynaptic mechanism involving TrkB. J Neurosci 20:6888-6897.

Zafra F, Hengerer B, Leibrock J, Thoenen H, Lindholm D (1990) Activity dependent regulation of BDNF and NGF mRNAs in the rat hippocampus is mediated by non-NMDA glutamate receptors. EMBO J 9:3545-3550.

Zhang J, Zhang D, McQuade JS, Behbehani M, Tsien JZ, Xu M (2002) c-fos regulates neuronal excitability and survival. Nat Genet 30:416-420.

Zhu JJ, Esteban JA, Hayashi Y, Malinow R (2000) Postnatal synaptic potentiation: delivery of GluR4-containing AMPA receptors by spontaneous activity. Nat Neurosci 3:1098-1106.

Zhu Y, Romero MI, Ghosh P, Ye Z, Charnay P, Rushing EJ, Marth JD, Parada LF (2001) Ablation of NF1 function in neurons induces abnormal development of cerebral cortex and reactive gliosis in the brain. Genes Dev 15:859-876.

Zhuo L, Theis M, Alvarez-Maya I, Brenner M, Willecke K, Messing A (2001) hGFAP-cre transgenic mice for manipulation of glial and neuronal function in vivo. Genesis 31:85-94. 